\title{
PERCEPTION OF SENIOR FACULTY REGARDING FRAME FACTORS IN CURRICULUM CHANGE AT UNDERGRADUATE LEVEL IN MEDICAL AND DENTAL SCHOOLS
}

\author{
Muhammad Bakhtiar ${ }^{1}$, Almas Khattak $^{2}$, Usman Mahboob ${ }^{3}$, Maria Mufti ${ }^{4}$, Anum Bakhtiar $^{5}$
}

\section{ABSTRACT:}

\section{OBJECTIVES:}

To determine the perceptions of senior faculty regarding frame factors influencing curriculum change at undergraduate level in public and private medical and dental schools at Peshawar, Pakistan.

\section{METHODOLOGY:}

This was qualitative exploratory case study and senior faculty was interviewed regarding the frame factors influencing integration and changes in undergraduate medical curriculum. Data was collected through in-depth interviews. Transcription, thick description was analyzed, coding was done, and similar codes were converted into categories. Finally, themes were created and concluded by thematic analysis.

\section{RESULTS:}

A total of ten interviews were done that identified 52 open codes. These codes were merged into 19 categories that led to development of five themes of frame factors influencing the medical curriculum. The themes and categories were: Lack of proper resources including human, technical, financial and infrastructure (building, equipment); Environmental factors, which included cultural, political and social contexts, which if not supportive could influence the change in curriculum; Lack of supports from regulatory authorities; leadership; legal issues and fragmented assessment approach minimize the dream of the changes in curriculums.

\section{CONCLUSION:}

Intention to change the medical curriculum is the ultimate goal but it is unlikely to grasp better pace due to few bottlenecks such as resources, infrastructure, and cultural, political and legal issues.

KEYWORDS: Medical Curriculum, Frame Factors, Influencing Factors, Curricular Changes, Barriers

How to cite this article:

Bakhtiyar M, Khattak A, Mahboob U, Mufti M, Bakhtiar A Perception of Senior Faculty Regarding Frame Factors In

Curriculum Change at Undergraduate Level in Medical and Dental Schools. J Gandhara Med Dent Sci. 2021;8(4): 25-31

https://doi.org/10.37762/jgmds.8-4.252

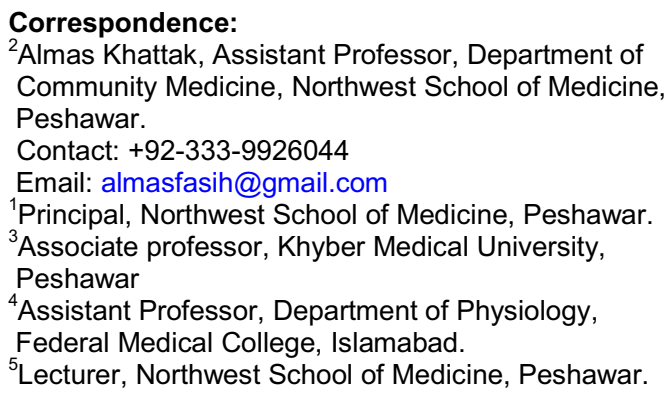

${ }^{2}$ Almas Khattak, Assistant Professor, Department of Community Medicine, Northwest School of Medicine, Peshawar.

Contact: +92-333-9926044

Email: almasfasih@gmail.com

${ }^{1}$ Principal, Northwest School of Medicine, Peshawar.

${ }^{3}$ Associate professor, Khyber Medical University,

Peshawar

${ }^{4}$ Assistant Professor, Department of Physiology,

Federal Medical College, Islamabad.

${ }^{5}$ Lecturer, Northwest School of Medicine, Peshawar.

\section{INTRODUCTION:}

The face of medical education is changing worldwide and Pakistan is no exception to it. The regulating bodies are actively encouraging the medical schools to gradually switch-over from the conventional teaching and learning style, to the integrated curriculum, which is more student centered, more interactive with less didactic lectures and minimum rote learning. Senior faculty have 
been teaching in the old traditional system for decades and hence their perceptions about the disciplined-based curriculum are oldfashioned and deep rooted. Due to advancement in medical sciences, a need is felt to review the curriculum and make it customized to the current needs ${ }^{1}$. Success is always preceded by a change and Flexner's era was the time where things started rolling down. The challenge to convert to the new integrated curriculum from an organ-systembased approach with vertical and horizontal integration is monumental ${ }^{2}$. The traditional faculty, however, received this wave of change with mixed feelings. After initial jet lag, they are gradually adjusting to the new environment to remain on the same page with national and international level ${ }^{3}$. Majority have taken steps of some kind to understand and adopt the curricular changes and the left over are also posturing to follow but still they need time, efforts and resources for full conversion. Few public and private sector medical schools have made tremendous progress at undergraduate level and the rest of the schools are making efforts to catch-up. The directives from regulating bodies are acting as catalysts for change. This joint effort of change at undergraduate level has an unwavering impact. The minds of the faculty are changing gradually and the perception of adopting the integrated curriculum is taking strong roots ${ }^{4}$. The change process of the curriculum at undergraduate level is a bit tough and difficult. It has definitely placed a challenge to the faculty but this challenge is well received, well taken and in the process of adaptation ${ }^{5,6}$. Due to its clear and visible benefits of making the student a critical thinker, a lifelong learner with clear focus on developing his/her attitude, knowledge and skills to make them true and thorough professional doctors are convincing and attractive ${ }^{7}$.Globalization and new innovation in medical sciences have obliged the students to remain updated to compete nationally and internationally, while nonabsorption these trends may affect their competencies $^{8,9}$. Thus, the adaptation of an integrated curriculum to develop holistic knowledge becomes their wisdom ${ }^{10}$. This learning approach also needs a facilitating environment to have an extreme concentration on the task. However, there are varieties of factors including the environment and internal and external factors, which influence both the students' learning and curriculum development by the faculty. The following are called "frame factors" and are broadly categorized into; Temporal, Physical, Organizational, Personal, Cultural and Social frames ${ }^{11,12}$. These frame factors have both positive impact if made available and promote the curriculum changes, while in case of failure; these may act as impediment for curricular changes, if already adopted. The objective of our study is to explore the frame factors in our context that are influencing the curriculum change for the undergraduate medical and dental programs.

\section{METHODOLOGY:}

We conducted an exploratory case study based on the paradigm of constructivism to address the objective of the study. The study participants were senior faculty members related directly to curriculum development, teaching, and administration in dental and medical schools. We used a purposive nonprobability sampling technique for selecting the participants. All the senior faculty members had basic qualification in health profession education with a minimum of 10 years teaching experience. After taking informed consent, the interviews were audiorecorded. We conducted one on one in-depth interview and kept the views of the participants confidential. The participants were allowed to talk freely, were listened to carefully and probed appropriately. To determine the sample size, we continued the in-depth interviews until we achieved the point of saturation at the tenth faculty member. We obtained ethical approval from the Ethics Committee of Khyber Medical University. The collected raw data consisted of direct quotations from the faculty members. We thoroughly read the transcriptions of the interviews and identified important concepts and quotations in individual transcripts to derive 52 codes. Codes were read; re-read, and similar codes were combined into categories that were further merged to form main themes.

The point of saturation was obtained at the tenth in-depth interview with senior faculty of four selected (two public and two private) medical and dental colleges. In order to identify various themes, we transcribed the interview probes followed by thick descriptions. Some of the codes were merged 
that were given to similar notions. Regarding job designation, nine were professors and one was assistant professor. Out of them, four professors were from dental and six from medical schools with a mean age of $45 \pm 10$ years.

\section{RESULTS:}

A total of 52 codes were generated that were combined into 19 categories that were further merged to form five main themes. Most of the participants perceived that changes in medical curriculum are the need of the hour in order to link different medical disciplines. As revealed from statement of a participant:

"As we know that we are living in a global village, there are so many changes in medical education in the world and we need to change accordingly" (P1 $\quad D$ D). The respondents accepted that most of medical and dental schools still follow the oldfashioned curriculum, as one of the participants stated:

"To be on the same page with the world, we shall change the curriculum to the current needs, which are prevailing in the world, especially in the western world" (P2 M). All the participants had the consensus that integrated curriculum should be opted as it provides active learning, is more student centered, has better outcomes (better doctor) but needs a multidimensional approach. This will bring positive changes through proper management and coordination. One of academician argued that: "Bringing changes in curriculum is the need of the hour. We have to go along with the world, where most of these changes have occurred".

Another one viewed that:

"Curriculum change shall be an evolution, rather than revolution".

The following major themes emerged as the participants addressed the issues related to different frame factors, both external and internal, in curriculum change at undergraduate level.

\section{Lack of Facilities and Resources}

All the participants strongly supported the idea to establish a fully functional medical education department, with trained human resource, equipment and ample infrastructure at each medical/dental school and should have a leading role for all medical education related activities. However, this move needs to be spearheaded centrally by the Pakistan Medical and Dental Council. Secondly, they emphasized on faculty development for bringing positive influence on curriculum change, as expressed by a professor:

"Large number of available traditional faculty is a hindrance. But resistance to change is gradually reduced after increasing the knowledge and awareness among newcomers".

Few participants pointed that: "The first task of the Department of Medical Education is to develop a strategic plan for itself and then for the college it has to serve".

\section{Another expressed that:}

"Old timers are bad timers in resistance". Men, material and money are the prerequisites for any change. This means that good organizational support affects positively and expedites the curriculum changes. All of the participants had agreed on the role of resources in terms of infrastructure and allied support. Conversely, it is going to be a hindrance in achieving the goals. One of participant stated that: "Money makes the mare go". Another participant said that: "For optimum teaching/learning, better organizational support structure produces positive influence on curriculum changes". Few of them were of the view that organizational structure hardly matters, only finances and economics play a key role. One faculty member added that: "We have seen this change but unfortunately, this whole exercise is resource intensive and both public and private sector medical and dental schools are not ready to induct the required level of human resource for students teaching".

\section{Environmental Factors (Cultural, Political and Social Contexts)}

According to the experts of medical education in the present study, political, cultural or social factors may have strong influence on the change process. One of the senior faculty members opined that: "The cultural factors include the traditional faculty, which got trained with traditional curriculum for decades, and cultural issues crop up from co-education where girls have outnumbered boys in medical 
schools. The former was a source of resistance for change to integrated curriculum and the later may result in sexual harassment". Another faculty member said that: "We belong to Khyber Pakhtunkhwa (KPK) where cultural and social values are deep rooted in our society. Ideas, customs and social behaviors play important roles in our lives. How does it affect the curriculum change? Our society teaches us to respect elders, be courteous to women and tender to children. There is a clear gender bias with more tilt towards males. The respect of senior faculty stops us from telling them to switch over to the integrated curriculum".

\section{Lack of Support from Regulatory Authorities}

The participants criticized Pakistan Medical and Dental Council (PMDC) for failing to ensure the international standards to improve medical education in Pakistan to come at par with new development in the world. It is high time that PMDC enforce strict, uniform and stringent standards to improve the quality of medical education in the country.

\section{Leadership and Legal Issues}

In the present study the results indicate that curriculum changes can be brought about conveniently if the institutional leadership is strong and in alignment with political and legal leadership. One senior faculty member stated that: "The role of Dean for change of curriculum is instrumental and very basic. Unless he is on the same page, nothing can move ahead nor can it gain any ground".

The Dean of the Institute or medical university manages change in curriculum with a shared leadership approach. He leads an organization, which looks up to his decisions for implementation and mobilization of logistics. During the curriculum change process, political and legal factors come across which are to be negotiated well and properly at the right time through strong leadership and good governance, skillfully and intelligently. The changes are not visible initially when there is lack of political or legal support. One participant suggested that:

"There is dire need that the administrative hierarchy of the institute needs to have strong links and coordination with all stakeholders in the chain of command for a smooth change process".

The positive influence of good governance acts as a force multiplier to progress. Two senior most faculty members' best described one aspect of the frame factors as:

"If standard instructions are being followed, rules and statues are not over stepped and law of the land is not violated, political and legal factors are going to help, instead of undermining you".

\section{Assessment Drives Learning}

The entire faculty opined that a harmonized standardized assessment is the only solution to success in the change process. However, for a single protocol of assessment for all students from different medical/dental schools, same curriculum should be taught with similar strategies of execution and implementation, as one of the participants argued:

"Changes at institutional level have greatly changed the behavior of students for problem solving. The mind and behavior are changing with these new tools of assessment like MCQs, SAQs, OSPEs and OSCEs. The issue is that the result of students studying in the traditional system will be influenced if they are assessed according to the principles of the modular system and vice versa".

They further added teaching and assessment at institutions must be aligned and uniform. They lamented the present state of affairs as only five colleges out of 23 are teaching and practicing the integrated system and the rest still follow the conventional system of teaching. One of the participants said: "Assessment has to be changed if the curriculum is changed. SEQs, OSPEs and OSCEs are good assessment tools. They are good for evaluation of a student's knowledge, skills and attitude. OSCEs and OSPEs shall be standardized and centralized".

\section{DISCUSSION:}

Curriculum reforms or modifications are in practice in developed and some developing countries of the world. The trend of changes in medical curriculum has gained momentum in developing countries in recent years; however, they are facing problems. Educational environment requires a clear vision with 
dedication from faculty and organization, therefore, it is important to mention that implementation of curriculum cannot take place without a conducive environment. The factors that influence curriculum change include the culture, expertise, working environment, resources, infrastructure, fair assessment, leadership, regulation and supervision. Using the exploratory case study, in this research, the authors identified various frame factors perceived by senior faculty for changes/reform and adaptation of new medical curriculum in medical and dental colleges in Peshawar. Frame factors are the external and internal factors that influence or enhance educational programs and curricula. As a conceptual model, it serves to collect, organize, and analyze information that is useful for the development and evaluation of medical curricula. The department of medical education is a very basic and fundamental intervention to any medical college. It is the lifeline of medical education and medical institutions cannot thrive without it ${ }^{13,14}$. Therefore, all the participants agreed that every medical and dental institution must have a fully functional and sustainable department of medical education (DME). They agreed that the DME should be fully staffed with qualified faculty, so that it remains fully functional and vibrant to deliver. Unfortunately, very few medical schools have such setups. The need for establishing a medical education department has been strongly addressed in the Association for Medical Education in Europe (AMEE) Education Guide ${ }^{15}$. The traditional faculty who is teaching the disciplined based curriculum from decades needs to be trained in terms of providing them with medical education courses such as, Certificate in Health Profession Education (CHPE), Master's in Health Profession Education (MHPE) and even PhD, where possible. Medical educationists have to improve the overall quality of assessment by implanting trans-examination, quality assurance procedures ${ }^{16}$. These procedures range from faculty development to execution of post exam analyses and dissemination of feedback to departments and students. The results of the present study indicated that resources, especially the lack of technical, human resource and infrastructure, were the key factors which influenced the adaptation of the new curriculum changes. The same is also reported by previous research studies. They concluded that resources lay the foundation for any change in curriculum, as it provides the basic ingredients, which are an integral part to the whole process of change ${ }^{17,18}$. In the present study, the findings indicate that changes in curriculum can be conveniently implemented if the institutional leadership is in alignment with political and legal leadership. Issues such as weak leadership and legal impediments influence the efforts for curriculum change and can strongly hinder decision-making. The findings from a study carried out by Jorgensen (2016) are consistent with the present findings that conclude that a leader has to articulate freely and forcefully with logic and arguments to get the job done ${ }^{19}$. It goes the same for a Dean of a medical college. Unless he is on the same page, nothing can move ahead nor can it gain any ground. The Dean of the institute or medical university manages curriculum change with a shared leadership approach, as also evidenced by studies ${ }^{20}$. They were further of the views that all these changes require official orders from the higher regulating bodies such as PM\&DC and that it needs to undertake the curricular reforms and changes very proactively. Similarly, administrative support from organizations also play a vital role for smooth running of the process ${ }^{21}$. Similar findings were also reported in health care settings where shared leadership management models (teams performing tasks) were found meaningful ${ }^{22}$. Even teaching leadership as a course is also effective in medicine, so no one can deny the role of leadership in bringing change in curriculum ${ }^{23}$. During the curriculum change process, political and legal factors come across which are to be negotiated well and properly at the right time, again through strong leadership, good governance, skillfully and intelligently. The participants were more critical about the assessment protocol of the new curriculum. The participants further expressed that it is unjustifiable if they teach according to an integrated system and assess students based on the old conventional system. At the same time, they also suggested that we needed to change the examination system and make necessary rules and regulations for that. In medical education, there are tools and various methods for assessment of knowledge, skills and attitude ${ }^{24-26}$. 


\section{LIMITATIONS:}

Due to the qualitative nature of the study, we could not assure the quality of study for transferability. However, the data was collected from a wide range of professionals and the reader can appreciate the findings that may be applicable to their educational context.

\section{CONCLUSION:}

The pace of changes of the integrated curriculum is slow due to lack of trained faculty, adequate resources, insufficient infrastructure, weak or non-existent DMEs and strong leadership, which is further compounded by cultural, legal, social impediments, lack of support from regulatory authorities and faulty assessment protocols. Coordination between all the stakeholders needs to be re-visited, re-enforced and aligned to get the desired goals.

\section{ACKNOWLEDGEMENT:}

We would like to thank all the esteemed faculty members for their participation in the in-depth interviews.

\section{CONFLICT OF INTEREST: None}

FUNDING SOURCES: None

\section{REFERENCES:}

1. Wang $\mathrm{Y}$, McKee $\mathrm{M}$, Torbica $\mathrm{A}$, Stuckler D. Systematic literature review on the spread of health-related misinformation on social media. Soc Sci Med. 2019;240(112552):1-12.

2. Royer DF, Kendall JL. Clinical educators' views of a paired anatomy teaching assistant and clinician teaching model for ultrasound training during gross anatomy. FASEB $\mathrm{J}$. 2017;31(S1):581.10.

3. Athinarayanan R, Newell B, Garcia J, Ostanek J, Diao X, Sundararajan R, et al. Learning in context with horizontally \& vertically integrated curriculum in a smart learning factory. Procedia Manuf. 2019;31:91-6.

4. Khan AA, Asher A, Ahmad A, Iqbal S, Khan NA. Frame factors for implementation of integrated curriculum in public sector medical college-faculty's perspective. Pak Armed Forces Med J. 2016;1(6):891.

5. Schamroth A, Schamroth J. Medical students' attitude to the teaching of medical humanities. Med Ed Publ. 2018;7(2):20.

6. Peterkin $A$, Beausoleil $N$, Kidd $M$, Orang B, Noroozi H, Brett-Maclean P. Medical humanities in Canadian medical schools: progress, challenges and opportunities. In: Routledge handbook of the medical humanities. Routledge; 2019. p. 364-79.

7. Quintero GA, Vergel J, Arredondo M, Ariza MC, Gomez P, Pinzon-Barrios AM. Integrated medical curriculum: advantages and disadvantages. J Med Educ Curric Dev. 2016;3:133-7.

8. Mishra S. Do we need to change the medical curriculum: regarding the pain of others. Indian Heart J. 2015;67(3):187-91.

9. Nguyen LH, Bank I, Fisher R, Mascarella $M$, Young M. Managing the airway catastrophe: longitudinal simulation-based curriculum to teach airway management. J Otolaryngol Head Neck Surg. 2019;48(1):1-9.

10. Arisanti N, Arya IF, Amelia I, Mutyara $\mathrm{K}$, Setiawati EP. Evaluation on the implementation of rural-based program for undergraduate medical student. Global Med Health Commun. 2018;6(2):148-54.

11. Verdonk P, Janczukowicz J. Editorial: diversity in medical education. Med Ed Publ. 2018;7(1):1.

12. Persson A. Framed school: frame factors, frames and the dynamics of social interaction in school. Scand $J$ Educ Res. 2015;59(5):499-514.

13. Shehzad S, Waheed Z, Kabir SK, Ilyas M, Farooq A. Students feedback about lecture rooms to improve the effectiveness of the lectures. J Gandhara Med Dent Sci. 2019;6(1):19-22.

14. Gazzaz ZJ, Baig M, Al Alhendi BS, Al Suliman MM, Al Alhendi AS, Al-Grad MS, et al. Perceived stress, reasons for and sources of stress among medical students at Rabigh medical college, King Abdulaziz university, Jeddah, Saudi Arabia. BMC Med 
Educ. 2018;18(1):1-9.

15. Batool S, Raza MA, Khan RA. Roles of medical education department: what are expectations of the faculty?. Pak J Med Sci. 2018;34(4):864.

16. Latif MZ, Wajid G. Reforming medical education in Pakistan through strengthening departments of medical education. Pak J Med Sci. 2018;34(6):1439.

17. Brinkman DJ, Tichelaar J, Okorie M, Bissell L, Christiaens T, Likic R, et al. Pharmacology and therapeutics education in the European Union needs harmonization and modernization: a cross-sectional survey among 185 medical schools in 27 countries. Clin Pharmacol Ther. 2017;102(5):815-22.

18. Lammerding-Koeppel $M$, Giesler $M$, Gornostayeva M, Narciss E, Wosnik A, Zipfel S, et al. Monitoring and analysis of the change process in curriculum mapping compared to the national competency-based learning objective catalogue for undergraduate medical education (NKLM) at four medical faculties: part I: conducive resources and structures. GMS J Med Educ. 2017;34(1):Doc7.

19. Jorgensen R. Curriculum leadership: reforming and reshaping successful practice in remote and regional indigenous education. In: Johnson G, Dempster $\mathrm{N}$, editors. Leadership in diverse learning contexts. Springer, Cham; 2016. p. 275-88.
20. Hromas R, Leverence R, Mramba LK, Jameson JL, Lerman C, Schwenk TL, et al. What a medical school chair wants from the dean. J Healthcare Leadership. 2018;10:33.

21. Döös $M$, Wilhelmson L, Madestam J, Örnberg Å. Shared principalship: the perspective of close subordinate colleagues. Leadership Policy Sch. 2019;18(1):154-70.

22. De Brún A, O'Donovan R, McAuliffe E. Interventions to develop collectivistic leadership in healthcare settings: a systematic review. BMC Health Serv Res. 2019;19(1):1-22.

23. Sonsale A, Bharamgoudar R. Equipping future doctors: incorporating management and leadership into medical curriculums in the United Kingdom. Perspect Med Educ. 2017;6(2):71-75.

24. Robinson BK, Dervin A. Teach to the student, not the test. Urban Educ Res Policy Annu. 2019;6(2).

25. Jacobs JC, van Luijk SJ, van der Vleuten CP, Kusurkar RA, Croiset G, Scheele F. Teachers' conceptions of learning and teaching in studentcentred medical curricula: the impact of context and personal characteristics. BMC Med Educ. 2016;16(1):244 .

26. Sethi A, Javaid A. Accreditation system and standards for medical education in Pakistan: it's time we raise the bar. Pak $\mathrm{J}$ Med Sci. 2018;33(6):1299-1300.

\section{CONTRIBUTORS}

1. Muhammad Bakhtiar- Concept \& Design; Data Acquisition; Data Analysis/Interpretation; Drafting Manuscript; Critical Revision; Supervision; Final Approval

2. Almas Khattak - Concept \& Design; Data Acquisition; Data Analysis/Interpretation; Drafting Manuscript; Critical Revision; Supervision; Final Approval

3. Usman Mahboob - Concept \& Design; Data Acquisition; Data Analysis/Interpretation; Drafting Manuscript; Critical Revision; Supervision; Final Approval

4. Maria Mufti - Concept \& Design; Data Acquisition; Data Analysis/Interpretation; Drafting Manuscript; Critical Revision; Supervision; Final Approval

5. Anum Bakhtiar - Concept \& Design; Data Acquisition; Data Analysis/Interpretation; Drafting Manuscript; Critical Revision; Supervision; Final Approval

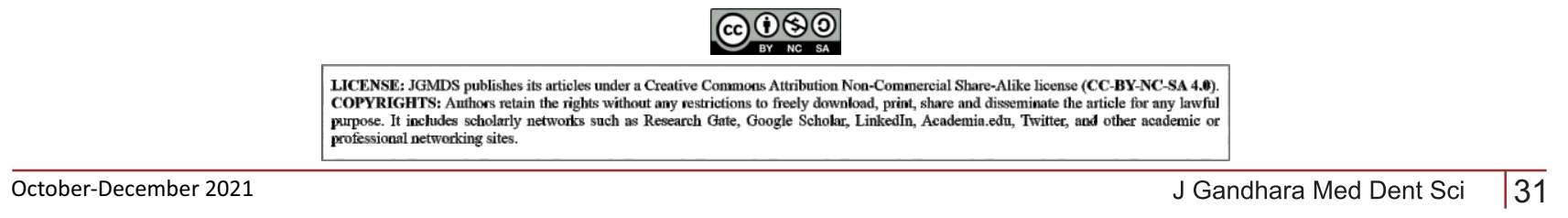

